\title{
Digital literacy: A sociological analysis
}

\section{Kerri Rinaldi}

\begin{abstract}
This paper analyzes how sociological factors, access to literacy, and self-sponsored digital literacy are interrelated. By reviewing New Literacy Studies literature and statistical analyses of digital communication usage, this paper gives a sociological reading to self-sponsored digital literacy. Literacy as a whole is an important facet to modern society, but we must acknowledge the rise of digital textuality as a new form of literacy and recognize the profound relationship that exists between socioeconomic factors and writing. This paper demonstrates that digitally produced writing is textually valid, steeped in social capital, and is extraordinarily accessible regardless of social factors, especially socioeconomic status. Based on these conclusions, implications for pedagogical instruction are also explored.
\end{abstract}

\section{Introducing the Overlap}

A student begins her day by sending a text message to her boyfriend confirming plans to meet after school. During the school day she sends multiple text messages to various friends about her day or the latest gossip. She remembers a report that is due soon, and makes a written note of its deadline in her cellphone's calendar. After school, she checks her Facebook and writes on a friend's wall. Later that night, as she struggles with her homework, she sends a quick email to her teacher requesting further explanation.

Each of these acts a typical student might engage in is certainly writing - the student is using the written word to communicate an idea either to herself or another person. However, they all take place in various digital formats, textual input channeled by a digital device such as a cellphone or a laptop. The student engages with digital text numerous times a day and with extraordinary ease. In fact, digital writing is the primary way she communicates with her friends and adults in her life. What does it mean to be so comfortable with these types of writing in these types of social contexts?

The simplest way to define this is digital literacy, or the ability to communicate effectively with text that exists in digital contexts. Student usage of the Internet and cellphones is nearly ubiquitous in present-day America-78\% of teens ages 12 to 17 own a cellphone, and 93\% use the Internet regularly (Madden, Lenhart, Duggan, Cortesi, \& Gasser, 2013; Zickuhr, 2010). The field of literacy instruction acknowledges the rise of digitally produced text, and has started to consider it when examining the validity of self-sponsored (defined by New Literacy Studies as extra-institutional writing that is self-initiated) texts. The study of the sociology of literature is a field that is also currently being rejuvenated, and it tackles such issues as the history of the book, sociological critique of literary aesthetics, the relationship between socioeconomic forces and the publishing 
industry, and the rise of the digital humanities. I approach my analysis with a question that draws from both of these fields: what if we were to take the tools of sociological analysis of literature and apply this type of examination to literacy, and in particular, self-sponsored digital literacy? It is my aim to take these two emerging fields and join them in a manner that gives a sociological treatment, one that is garnered from the concepts of critical literary theories, to literacy in such a way that it is a new interdisciplinary application.

This sociological reading given to digital literacy diverges from prior traditional applications of social and cultural theories to literacy studies by focusing on topics important to the fields of sociology, literature, and literacy instruction. Such topics include the transition towards primarily digital textual communication, class status, and access to literature. Each of these areas undoubtedly affects literacy, and therefore has implications for literacy instruction. By framing this analysis as one that draws from the fields of sociology and literature, I make connections to pedagogy and tease out implications for it, motivated by the extraordinary changes both literature and literacy are undergoing as we transition towards a digitized society.

This digital transitioning of our society brings about new forms of literacy that raise serious questions: how does this shift to high digital literacy inform access to literature, questions of textual validity, and ultimately, pedagogy? What are the sociocultural implications of new digital literacies, and how can we use these implications to shape our literacy instruction? These questions are significant for the field of sociology as well as for educators, and are deserving of inquiry as the field of literacy changes as a result of the transition towards digital textuality and the trend towards students who are most at ease with digitally produced text. If we hope to understand this transition in such a way that we can enlighten our pedagogical instruction, it is imperative to examine the ways in which sociological and economic factors interact with digital texts and literacy.

\section{Theoretical Framework}

A theoretical framework for conceptualizing social status that can be applied to understanding the meaning and value of social actions-like writing-is that of the renowned contemporary sociologist Pierre Bourdieu. Bourdieu (2008) theorizes that capital is not only economically accumulated and exchanged, but that it also appears in objectified or embodied forms that can be accumulated and exchanged just as economic capital is. He terms these intangible types of capital as symbolic, which can be further divided into two groups: social or cultural capital. The former refers to societal status, networks, connections, and the like. Cultural capital is further broken down into embodied, objectified, or institutionalized capital. These types of capital - which can include one's accent, disposition, books owned, degrees, or institutional pedigree-take time to accumulate and have an intimate relationship with wealth. According to Bourdieu (2008), all forms of capital must be acknowledged in order to understand the structure of the social world. 
In the field of the sociology of literature, Alan Liu's work looks at the ways in which the new digital age interacts with the humanities and literary instruction. In his work From Reading to Social Computing, Liu (2010) states that social computing is a repurposing of the social functions of reading and literary activity and should be given treatment in literary scholarship, because it is a vital coming-together of the personal experience of language. He proposes that we should also employ a new set of methodologies that are interdisciplinary, new analytical tools that are made possible by the digital age, and most importantly, new pedagogies.

To set the stage for how we will approach and situate the concept of literacy, Cook-Gumperz's work in literacy research will be used. For Cook-Gumperz (2006), historical and social contexts are inseparable from our conception of literacy: how we as a society view literacy is highly contingent upon the social, historical, and cultural environment in which we are considering it. She conceptualizes literacy in the way that is commonly accepted in the field of New Literacy Studies. That is, there is not one universally accepted, autonomous literacy, but rather multiple literacies, each functioning distinctively and holding different values in varied social and cultural contexts. Through her historical analysis of literacy education, CookGumperz (2006) highlights how intimately related societal conditions, including dominant class ideology and social control, are to literacy instruction. Her work stresses the relationship between literacy, perceived values, and how literacy serves as a function of cultural power in societal contexts, which will be useful for providing a framework for understanding value-making and cultural status as it relates to digital literacy.

The relationship between writers of digital text and the writing they produce is carefully mediated by institutional influence-institutions of literary convention, institutions of socioeconomic status, and institutions of social relationships. Writing is inherently a social practice, an acknowledgment that forms the basis for orienting this analysis. When we consider literacy as a pedagogical practice, and champion its importance for success and knowledge-building in our society, we must not lose sight of the fact that being literate is not merely a means of gaining knowledge and success. The ability to write is ultimately the ability to be social via the written word-to communicate with others in textual form.

The sociology of literature has analyzed genres of literature, and this paper is predicated on the notion that the same type of analysis is possible for categories of literacy. Various forms of social computing can be categorized as genres of writing, according to Liu (2010), and this paper expands that idea to posit that all forms of digital writing could be classified as such, including text messages and emails. Not only could these assorted types of digitally produced writing be considered genres, but the ability to be literate in each context amounts to different possible literacies; one who is well versed in digital writing in a texting format is texting-literate, one who is well versed in a blog format is blog-literate, and so on. Though these can all fall under the general umbrella of digital literacy, there are still different conventions and rules in each digital context, thus mimicking the classification of genres. 
This paper provides a sociological analysis of digital literacy by combining the theoretical frameworks of Bourdieu-paying particularly close attention to his concept of social capital as it pertains to group memberships and peer relationships-with that of New Literacy Studies-which promotes the pluralization of literacy, or the idea that there are multiple literacies one can possess, each of which can hold value in different cultural contexts-and with that of the sociology of literature, which posits that even within the broader umbrella of digital literacy, there are several forms, or genres, of digital writing with whose conventions one may be familiar.

\section{Scope and Definitions}

This paper's focus is narrowed in its approach to digital literacy, as this is often the broad catchall term given to being literate in computer use. For our purposes, however, this paper concentrates on those who are not only computer literate (can operate a computer with ease, and navigate the Internet and forms of digital communications), but are also highly literate in digital rhetoric, or the specific style of writing that is ubiquitous in digital communication. The specific contexts in which literacy events take place, especially when they are forms of social communication, have implied conventions, rules, and structures that guide the writing within each context. The digital sphere is no exception: in order to be digitally literate in the rhetoric of this format, one must at least be aware of and able to navigate the conventions and norms of digital writing. I use the terms digital writing and digital rhetoric to signal the writing style that takes place in digital contexts. One final caveat on terminology choice: while I often refer to digital literacy as a singular concept, I recognize that it is not a single autonomous or individual literacy, just as traditional literacy is not. Rather, digital literacy also refers to multiple different possible literacies within the digital sphere. For clarity, when I use the term digital literacy, I mean all types of writing that occur in digital contexts.

\section{Analysis}

\section{Questions of Textual Validity}

Just what it means to be literate has been a question painstakingly debated in the education field since the first attempts to define literacy, and its definition has been fluidly changing shape over time, influenced by theoretical reimaginings of what it is that literacy is and does. Cook-Gumperz (2006) states that it is generally accepted by both educators and the public at large that literacy plays "a major role in the improvement of the quality of life for individuals, social groups and even for whole societies" (p. 19). In the past, functional literacy, or the literacy level necessary to function in society, has been loosely defined as the ability to read, write, and do basic calculations, as well as the ability to create new comprehensible written materials. Cook-Gumperz (2006) rightfully points out that such a definition is inherently freighted with cultural bias and implicit evaluations. The previously accepted definition of literacy was not only overly simplistically reduced, with implied cultural evaluative standards, it was also presented as a neat dichotomy. Literacy was regarded as the skill of reading and writing-that is, either you could 
read and write and were literate, or you could not, and you were considered illiterate (Purcell-Gates, 2007).

Literacy was also heavily tied to institutional authority; it was thought of as a decontextualized skill learned in one specific setting-the classroom-and a lack of access to such an institutional setting meant a person was more likely than not to be regarded as illiterate (Purcell-Gates, 2007). However, this reductionist, institutionally laden definition of literacy has fallen by the wayside in the past thirty years. Brian Street (1984) was among the first scholars to suggest that literacy was not an autonomous, decontextualized, singular skill, but rather an ideological construct defined by the social institutions and groups in which it occurs. This initiated a theoretical move towards thinking about how literacy is socially constructed and determined by specifics: localities, contexts, and social practices (Purcell-Gates, 2007). Literacy is no longer regarded as a singular, independent concept, but rather as a contextualized, pluralistic set of many literacies. This is referred to in the field of New Literacy Studies as multiple literacies or multiliteracies. In this pluralized state, different literacies are accorded different values, legitimacy, and status, all dependent upon the institution or context in which that literacy takes place. Put simply, we now recognize that there is not merely one literacy that a person can either definitively do or have, but instead, a person has several literacies, and can be literate in several different contexts, each of which are valued in a certain space or by certain people.

Given this new vantage point, there is no one universal definition of functional literacy, and providing a technical definition of literacy is now regarded as a near impossibility. What was once thought to be the correct singular version of literacy is now often referred to as Standard English literacy (specifically, the ability to be able to read and write in Standard English) or academic literacy (specifically, the ability to be able to employ Standard English critically in an academic context). From the multiliteracies perspective, academic literacy is no longer considered the only literacy a person can achieve, or the only literacy that has value or that matters; rather, it is merely one type of literacy that is given meaning and status in the narrowly specific context of the academic institution (Purcell-Gates, 2007).

As a whole, literacy practices are patterned by the personal and social everyday lives of people: they make lists for grocery shopping, write birthday cards to relatives, read instructions for taking medicine, and write in personal journals (Purcell-Gates, 2007). These are all examples of various types of literacy at play in everyday contexts. In our current time, people expend much of their literacy practices on social digital writing. This is especially true of our youth, who have come of age with such modes of communication as dominant.

In terms of validity, a more level playing field arises from the idea that academic literacy is but one in a sea of many possible literacies. With the advent of the multiliteracy ideology, nonacademic literacies were no longer viewed as deficient to mainstream academic literacies, only as different (Cazden et al., 1996; Purcell-Gates, 2007). Academic or Standard English literacy, as is argued by multiliteracy proponents, should not be regarded as the one correct form of writing. 
After all, "[t]he emphasis upon grammar and correctness is," notes Cook-Gumperz (2006), "a historical feature of our society based upon the historical accident that the written literate language was different from the spoken vernacular at critical historical periods" (p. 45). Barton (2000) warns us, as well, that we must avoid the thought that there is some sort of natural form of language or literacy, one that is untouched by social institutions or cultural power dynamics. Those types of literacies that are contextualized and valued outside of the school setting began to influence pedagogical considerations. Extra-institutional literacies were termed vernacular literacies, and educators searched for ways to make use of these selfinitiated literacies in the classroom as a means to increase academic literacy.

Miriam Camitta (1993) points out that vernacular writing, or what she terms self-sponsored writing, is "literate behavior that conformed, not to the norms of educational institutions, but to those of social life and culture" (p. 229). In her work at a Philadelphia high school in the early 1990s, Camitta (1993) realized that while her students rarely produced writing for their teachers in the classroom, they engaged heavily in extra-institutional writing, primarily for social purposes. At that time, self-sponsored writing included journaling, passing handwritten notes between friends, and transcribing rap collaborations. Though the classrooms of today differ from those of the early 1990s, the same can be said of contemporary students' writing practices, to an even greater degree. Even those students who produce little in the way of academically sanctioned writing (or are thought to have a low level of academic literacy) are likely to engage heavily in writing practices with their social group that are self-initiated-a majority of contemporary students write emails, text messages, and social media content—in short, digital rhetoric —on a daily basis.

What does digital rhetoric actually look like? To be sure, just like other forms of literacy that are different from Standard English literacy, it is not so far removed from standard literacy that it is unintelligible to the untrained eye; rather, it employs certain aesthetic characteristics and conventions, which appear frequently but are not necessarily a requirement. In an ethnographic study of written language used in instant messaging (or IM) by teenagers aged 12 to 17, David Craig (2003) identified four characteristics that regularly appear to differentiate and demarcate digital rhetoric. These four categories were phonetic replacements, or the usually shortened form of a word with its phonetic letter equivalent (e.g., ur for your); acronyms (e.g., omg for oh my god or lol for laughing out loud); abbreviations (e.g., ppl for people); and finally what Craig termed inanities, or nonsensical transmogrifications of words or other digital textual conventions that were purely a play on words, yet that still suggested a certain meaning or tone (e.g., lolz).

Craig (2003) remarks on how such conventions of digital writing seeping into other contexts, especially the institutional setting, have garnered negative comments about the devolution of the language and literacy skills of our youth, with most of the blame placed on the advent of technology. Ultimately, he resists the idea that the Internet and cellphone usage are to blame for the perceived decline of literacy, arguing that being literate in what he calls a "lowbrow vernacular" does not 
damage a student's writing ability. This is because, in congruence with multiliteracy ideologies, being literate in one context does not preclude a student from developing a wide array of different literacies, academic literacy included. Being digitally literate actually benefits the student, Craig argues, by promoting regular contact with words and regular contact with a written medium of communication. Not only is regular contact with the written word fostered, but the focus on communication in written form helps students develop skills that are imperative for other forms of literacy, academic included. After all, one cannot communicate via text message or IM if the message is unintelligible, or if the spelling is so mangled or the syntax so jumbled that the intended meaning does not transmit. Despite the use of shortened spellings and other conventions that are held in esteem in their social group, the digitally literate are still writing in a manner that clearly communicates what it is they are trying to say-an important feature of literacy as a whole.

According to John Frow (2010), such a sociological consideration of different forms of writing allows us to undo the coherence of social systems that appear to neatly favor some particular cultural distinctions over others. From this vantage point, and also in accordance with New Literacy Studies, we can unravel the presupposition that academic or Standard English writing is the correct manner of writing with the highest value or prestige. In doing so, the class and economic attachments to certain forms of literacy are exposed: academic discourse is strongly correlated with value-making in middle and higher classes, while digital discourse is strongly correlated with value-making in youth social peer groups-a point which I will explore more in the next section.

Despite some teachers' or policy makers' laments that digital rhetoric is devolving language and impeding literacy, it is imperative that we look at digital literacy from the perspective of multiliteracies. While digital rhetoric is surely changing the written word in ways we never predicted (something that is easy to resist), digitally produced writing must be viewed as yet another type of literacy, one that is highly contextualized with its own set of social norms and values. Digitally mediated text is extraordinarily social, and thus richly imbued with the social underpinnings that New Literacy Studies regards as informing all literacy contexts. Liu (2010) has even admitted to at times being dismayed by the state of language, yet he reminds himself that it should be our aim to look at language where it is most lively and most social:

It is to follow the living language of human thought, hope, love, desire, hate, and wit wherever it goes and wherever it has the capacity to be literaryeven if the form, style, or even spelling and punctuation of such literariness does not conform to those stabilized in the relatively brief period of high literature roughly between Shakespeare and Joyce. (para. 26)

The multiliteracy perspective would determine digital writing as a valid form of literacy that is socially constructed to have its own meaning and status in its digital contexts. Digital rhetoric, in essence, is textually valid. 


\section{Social Status and Literacies}

Having established the textual validity of digitally produced writing, we can now turn our attention more closely towards digital literacy as a social practice and interrogate the relationship between its sociological factors and its use. As it is a socially constructed event, a certain type of writing gains widespread use in a specific context because within that context, it has social value and status attached to it. From where do such meaning-making and status derive in digital rhetoric? How does this value translate to pervasive use in digital contexts? More importantly, what role does digital literacy's socially assigned status and value play in its use in academic contexts?

Before we are able to tackle such questions, it would be useful to explore the connection between socioeconomic factors and literacy in general, with an emphasis on academic success. Time and time again, research has shown that the sociological factor with the strongest influence on literacy and academic success is class status (Lareau, 2011). While other sociological factors such as race, gender, and citizenship play a strong role, economic status has been found to be the strongest influence on academic success and literacy, and though the gender and race gaps have steadily been closing, the gap in literacy skills due to socioeconomic disparities only continues to widen (Lareau, 2011; Reardon, Valentino, \& Shores, 2012). Likewise, household income is the strongest predictor for Internet and cellphone usage across all age levels (Smith, 2010), an important similarity that will be useful for our purposes.

By investigating the relationship between educational success and class status, Annette Lareau (2011) discovered that it is a distinctive difference in cultural child rearing, which she concluded led to a difference in cultural values, that is the link responsible for socioeconomic status's effect on academic success. The middleand upper-class families Lareau studied followed a strategy of child rearing she termed "concerted cultivation"-children were communicated with as if they were equals, and were encouraged to ask questions, challenge assumptions, and negotiate rules (2011). Working-class families, on the other hand, employed the "accomplishment of natural growth" strategy, which gave children more freedom to play and interact with their social peers, but included instruction to defer to adults and treat them with quiet, revered respect (Lareau, 2011). Both strategies were employed subconsciously by parents as a means to instill cultural values that were esteemed and deemed worthy of transference in their respective socioeconomic classes.

It is important to note here the relationship between the concerted cultivation strategy of child rearing and academic success. Lareau (2011) found that the values encouraged by this strategy were the same values that are specifically held in esteem by the upper class. Being exposed early to such values acted as cultural capital for children in middle- and upper-class families and benefited them academically, since these values are conducive to successfully operating in a manner congruent with academic success. Students from these social classes learn to develop and value cultural practices that are valued by the dominant class, like high 
Standard English literacy, precisely because their socioeconomic class recognizes these practices as cultural capital.

Questioning, negotiation, and authority testing were frowned upon in the accomplishment of natural growth method, and yet these are precisely the values that successfully translate to academic contexts, since academic institutional values are closely matched to the values of the hegemonic ideology (Lareau, 2011). The ability to question and negotiate with authority, especially when cultivated from a young age, translates to the ability to question and negotiate with knowledge, and with authority in knowledge-in other words, the ability to engage masterfully in critical analysis. The values instilled in working-class children are effective for navigating social relationships in their family and social units, but in the academic world, these values do not hold an advantage. In the academic and professional world, the ruling-class ideology prevails, and the qualities developed by upper- and middle-class children are valued much more strongly over the ones developed by working-class children. The lesson we can take away from Lareau's study is that different cultural practices are given different values, particular to social and institutional contexts. The values of the dominant upper class have a striking similarity to the values of academic institutions. This helps to explain why the dominant upper class values Standard English literacy, and why academic institutions do as well. To be sure, the institution of academia is a complex set of contexts with values that vary by location, mission, prestige, and other markers. However, it is sufficient for our purposes to conclude that the academic institution as a simplified entity (be it a public grade school, a private high school, a community college, or an ivy league university) consistently values Standard English literacy above all other types of literacies. A person's class has a strong influence on the cultural values that are fostered and encouraged, and if these values do not match those of the dominant academic ideology, the student is at a preemptive disadvantage.

Now that we have drawn out the relationship between academic literacy and social and cultural values, we can examine a similar influence of such values on the use of digital rhetoric. In drawing from theories of multiliteracies, we know that certain styles of writing and modes of speech are used in specific contexts because they benefit the user in that context. Vernacular forms of English are used in speech and writing as a means of asserting membership within a community, familiarity with the social norms and values of the community, and as an identity-making tool. By using the type of literacy that is valued in a specific context, one reaps benefits in the form of recognition as a member of that community. The ability to correctly and masterfully use the category of literacy and language associated with the values of a particular context, or 'field' in Bourdieu's terminology, is a form of cultural capital (2008). Those students who employ digital rhetoric in socially communicative contexts do so because it is a form of capital-it establishes their knowledge of the norms and rules of their social peer group, and is palpably beneficial to them via social acceptance. More succinctly, the ability to produce digital text is a means of asserting their place in their peer group, a membership from which they reap nearly immediate social and personal rewards. 
It is this cultural legitimacy that causes digital rhetoric to be used in nondigital contexts. Students see the legitimizing power of being digitally literate in their social circles: knowing how to communicate digitally and use the rhetoric solidifies their position as an in-the-know member of the community. If the benefits of digital literacy as cultural capital in their social group are clear to students as an important part of their social identities, it follows that employing such digital rhetoric might be seen as more beneficial than engaging in Standard English literacy, the benefits of which are not so immediately clear. By placing greater emphasis on their social status in their peer group, it makes sense that some students would not make it a point to code-switch between literacies, or would fail to see the benefit of dropping text speech in contexts outside of their social fieldtheir digital literacy legitimizes their social standing. Using digital rhetoric outside of digital contexts is therefore not merely a result of comfortability with certain types of writing, but rather a carrying of social prestige from one context to another, the decisive questioning of the benefits supposedly promised by adapting to a different type of literacy. Digital writing, therefore, serves a distinct social function for students. Just as Frow (2010) proposes that "readers are formed by text as much as texts are formed by readers" (p. 247), writers are formed by their texts as much as their texts are formed by writers.

\section{Digital Literacy Access: The Digital Divide?}

The digital divide, the name given to the gap between those who have plentiful access to computers and the Internet and those who lack access, certainly exists across the globe, including within the American context we are inspecting here. In attempting to determine what type of sociological factors correlate with this divide, socioeconomic status (primarily income and education levels) stands out as a strong influence. For instance, those with a high school diploma or less schooling are much less knowledgeable about using the Internet than those with a college degree (Hargittai \& Hinnant, 2008). As previously stated, there are many sociological factors that influence and relate to digital literacy and rhetoric use, but the strongest predictor of whether a person engages in digital communication is socioeconomic status. Given the existence of the digital divide, how does socioeconomic status affect access to the various means for producing digitally mediated text? In the following section, I will examine statistical evidence of this influence and show that while the digital divide exists, access to contexts in which digital literacy occurs is abundantly widespread, regardless of sociological dynamics.

The Pew Internet and American Life Project has provided valuable data on the usage of the Internet and cellphones, and has mapped out trends in usage divided by sociological markers such as gender, income level, and age. Their research confirms the existence of the digital divide, as they note that higher income levels, specifically above the threshold of an annual income of $\$ 75,000$, is strongly correlated to higher Internet and cellphone usage. Of Americans earning above this income threshold, 95\% use the Internet; of those below the threshold, $70 \%$ use the Internet. Out of these Internet users, $99 \%$ above the $\$ 75,000$ income threshold use the Internet in their own home, and $93 \%$ of Internet users below the threshold use 
the Internet at home (Jansen, 2010).

These data do underscore the digital divide's existence and confirm that socioeconomic status is a strong indicator of access to digital contexts, and thus familiarity with digital literacy. But a distant reading, a sociological methodology encouraged by Moretti (2000) and others that exercises distance as a condition of knowledge about a social arena or practice such as digital writing, is apposite here. Not only will this introduction of distance into the textual analysis let us focus on units or classifications that are larger than the process of writing (or literary event) or the digitally mediated text itself, this step back also shows us that the influence of the sociological category is less than we might have imagined in the digital divide. Even among those Americans with a lower income level, Internet and cellphone usage is still extraordinarily widespread, signaling a strong likelihood-despite the acknowledged influence of socioeconomic status-of digital literacy among all income levels. Out of all adults that make under $\$ 30,000$ a year, nearly two-thirds still regularly use the Internet. The usage jumps sharply in the next income bracket: of those making between $\$ 30,000$ and $\$ 50,000$ annually, $80 \%$ regularly use the Internet (Jansen, 2010).

Not only is Internet use incredibly prevalent along the full spectrum of income levels and other sociological factors such as age and race, its primary functions for most users are communicative in nature. Email remains the number one functional use of the Internet for every age bracket among Americans, and fully 90 to $100 \%$ of Americans under the age of 74 use email (Zickuhr, 2010). This strongly suggests that literacy in digitized textual rhetoric is exceptionally prominent, and has a strong presence and role in the social and personal lives of the majority of Americans, regardless of sociological underpinnings.

Cellphones are even more remarkable in their flattening of hierarchal access to digital technology. Used for telephone calls, of course, but also for transmitting text messages, emails, instant messages, social networking, and sending and retrieving information via the Internet, cellphones are utilized in such manners by what amounts to virtually most of the population. Cellphone usage is incredibly widespread, regardless of race, age, or income level, and ubiquitous in our current society: $85 \%$ of all American adults own a cellphone, and of those who are under the age of 35, 95\% own a cellphone (Zickhur, 2011). Ownership is increasingly prevalent even among younger students, and by 2010, three-quarters of Americans between the ages of 12 and 17 owned their own cellphone (Lenhart, Purcell, Smith, \& Zickhur, 2010).

The $\$ 75,000$ income threshold indicator stands for cellphone usage just as it does for Internet use, but the gap here is even smaller: of those over the threshold, 95\% own cellphones, and of those below it, 83\% own cellphones. Even in the lowest income bracket, below $\$ 30,000$ in annual income, 75\% owned a cellphone (Zickhur, 2011). A specific Pew study on mobile usage among race and class even points out that cellphone ownership is higher among African Americans and Latinos than it is among whites (Smith, 2010). 
This pervasive usage of cellphones points towards a prevalence of digital literacy among all sociological sectors. Of all cellphone owners, nearly three quarters use it regularly to transmit text messages; that is, they engage regularly with and exercise their digital rhetoric literacy. Underage students are the most common users of this type of communication, with girls aged 14 to 17 in the lead (Lenhart, Ling, Campbell, \& Purcell, 2010). More than half of all teens send fifty or more text messages in a single day, and one in three sends more than 100 per day (Lenhart, Ling et al., 2010). Such widespread use is also seen in Internet usage with this age group: $93 \%$ of teenagers use the Internet for emailing, social networking, listening to music, and information retrieval (Lenhart, Purcell et al., 2010).

If we think of access to technology in purely physical terms, that is, physical access to a computer or cellphone, then indeed, nearly all Americans do have access to digital technology. Some scholars (Hargittai \& Hinnant, 2008; Warschauer, 2008), however, call for a broader view of access, stating that other forms of access inform the ability to use this physical access in a meaningful way. Warschauer (2008) concludes that in addition to physical access, other forms of access that are crucial for true accessibility to the digital arena include digital resources, or an adequate amount of meaningful content available that is culturally relevant to an individual; human resources, or the skills and know-how needed to use a computer in a meaningful way; and social resources, or the social structures necessary to support effective use of technology. Thus, it might be argued that just because American teens have nearly limitless physical access to a computer or cellphone, this does not necessarily imply high digital literacy or the ability to interact with a technological instrument in meaningful ways. However, if we look more closely at how students utilize their physical access to technology, we will see that types of functional usages that indicate digital literacy remain highly pervasive, including across class lines.

While $69 \%$ of teens report owning a computer, a full $95 \%$ of Americans ages 14 to 17 use computers in their homes, school, or libraries to access the Internet. Even more striking, $82 \%$ of teens ages 14 to 17 regularly use this time online to access social networking sites, and use these digital environments to send messages to friends, create short posts that are shared publicly, and comment on pictures and videos-all practices in digital rhetoric. Though a teen from a lower-income family may lack the forms of social capital necessary to successfully use digital technology for, say, performing academic research, this does not appear to be the case for online activities that indicate strong digital literacy. In fact, teens from families who earn less than $\$ 30,000$ per year are more likely to use online social networking sites than their wealthier peers (Lenhart, Purcell et al., 2010). This prevalence of social media site usage in conjunction with the pervasiveness of texting, regardless of socioeconomic status, shows not only functional ability, but also implies teens of all income levels engage with digital technology regularly in a manner that produces text, therefore signaling high literacy in the use of digital rhetoric. These forms of communicative usage are far more important in terms of socially esteemed digital literacy practices than other ways of using technology-which may indeed be influenced by other forms of access-that instead suggest other forms of literacies, such as academic literacy. 
Digital writing, especially in the form of text messaging, is the leading type of written communication used by youth students. A Pew study (Lenhart, Ling et al., 2010) has found that "text messaging has become the primary way that teens reach their friends, surpassing face-to-face contact, email, instant messaging and voice calling as the go-to daily communication tool for this age group" (Overview, para. 2; italics mine). This is a fascinatingly regular usage of and contact with the written word for purposes that are purely extra-institutional, socially motivated, and selfinitiated. We can then deduce that high school aged students are the leaders in digital literacy, and they typically employ this type of literacy with much more frequency than other institutional, personal, or social categories of literacy. In essence, they are truly masters of digital rhetoric and are extremely literate in the digital writing arena.

By offering a statistical exploration of the digital divide, I set out to demonstrate that even though economic factors are influential, the larger picture is that access to and participation in digital literacy are nearly ubiquitous, especially among students, regardless of socioeconomic positioning. Juxtaposed against the privileging of academic literacy as an ideology that maintains the power structure and marginalizes those lacking access to cultural capital, and thus impeding access to academic literacy (Purcell-Gates, 2007), the prevalence of digital literacy across socioeconomic factors stands out with a weighted significance.

Perhaps this indicates that not only is digital literacy a valuable pedagogical resource because of its vernacular literacy status, which is permeated with positive social and cultural value, but also because it exists as a form of literacy that is less influenced by institutional and socioeconomic factors in terms of access. Increased accessibility and literacy in digital rhetoric, regardless of class status or race, suggests that it is a highly valuable pedagogical resource, one that is worth mining as a means to increase both academic literacy-which is much more steeped in institutional and socioeconomic limitations to access-and literacy in general.

What can we make of the fact that nearly all students text message on a regular basis? Despite how conventions of digital literacy might differ from conventions of Standard English literacy, we should draw an optimistic hopefulness from the fact that students engage in self-initiated writing on a daily basis, and are highly skilled in using the written word to communicate in a social context. Because of digital writing's accessibility across socioeconomic statuses, it stands out as a form of literacy that is less influenced by one socioeconomic group's ideology, less hierarchal, and less rigid in its rules. This is because they are developed and legitimized by the heterogeneous users themselves, as opposed to Standard English literacy's rules, which are determined by a hierarchal and hegemonic power structure. In essence, digital literacy is a democratic form of literacy that nearly all students use with ease, making it a potentially powerful pedagogical tool. 


\section{Implications for Pedagogy}

\section{Former Assessments}

Purcell-Gates (2007) has written, “in response to the educators' question 'what does this say for instruction?' ... social literacy research does not necessarily have to say anything for instruction. Rather, much of this research stands on its own as literacy studies research and is interesting and significant in its own right" (p. 15). Whenever research on or analysis of literacy's connection to social factors occurs, the question always follows: how should this influence or change literacy instruction? Purcell-Gates makes a valid point: this research is significant in its own right and worthy of study without automatic attempts to implement findings into pedagogy. However, it still stands that by studying literacy, we are studying something that we regard to be intimately tied to the act of teaching and scholarship. If we change the way we think about or approach literacy, we ultimately are changing (or at least subtly influencing) the way we approach literacy instruction, and are expanding our pedagogical toolbox. For this reason, this paper's stand-alone significance should be noted, but we will also attempt to translate it to practical implications.

First, there certainly have been examples in the past of successfully marrying digital literacy (both of the digital rhetoric and the computer-usage literacy variety) and traditional critical academic engagement in the classroom. Liu (2010) provides several examples of using digital contexts his students are familiar with as a means to boost academic skills, such as close readings and critical analysis. He successfully merged social computing and literary analysis by using digital platforms, such as LiveJournal, an online journaling or personal blogging site that stresses community building, to study The Canterbury Tales. His students created a journal for each character, and then had characters comment on (and engage in dialogue with) other characters' journal entries in line with the plot. He also used Facebook, an extremely popular social networking site, to analyze Romeo and Juliet by creating a profile for each main character, and then had the students model the play by having characters friend the appropriate profiles, create events (complete with the appropriate invitations sent) that were integral to the plot, and post status updates, complete with replies, as the events transpired. These examples use a format in which the student is literate, and plays upon this resource to actively engage the students to explore and develop a critical understanding of the events and complex social relationships in each famous literary work. By tapping into the students' digital literacy, Liu was able to foster a deeper understanding of Chaucer and Shakespeare in his students. Not only did he focus upon his students' literacy in social computing in these examples, he also fostered a greater critical understanding of the texts visà-vis his students' literacy in digital writing - he was able to engage the students precisely because he encouraged them to write in the format and with the rhetoric in which they are already comfortable and literate.

More closely related to literacy instruction, Kristen Turner (2009) encourages educators to employ exercises that allow students to break down the correct contexts for each type of literacy, such as a worksheet in which students 
search their academic writing for examples of text-speak-defined by Turner as the informal, abbreviated, and often fragmented version of English widely found in text messages-record it, and "translate" it to its Standard English equivalent. She stresses that students should be made aware of their ability to code-switch between each type of rhetoric, and that engaging them in thoughtful analysis of their own word choices allows them to understand contextual use-specifically that Standard English is more appropriate for academic contexts, and text-speak for social digital contexts. The vast number of digital contexts that students use frequently (text message, IM, email, social networking, etc.) demonstrates that students have the ability to write for many different digital platforms, and code-switch between them well. These skills are transferable to academic literacy; moreover, code-switching between standard literacies and other forms of literacies is an important skill that should be tapped into and fostered.

Liu (2010) states that by employing social computing in academic instruction, "we expand or reconfigure the nature of reading"; similarly, it is not possible to suggest that we completely reinvent literacy instruction or literacy itself in an attempt to position self-sponsored digital writing in the literacy sphere (para. 46). Rather, my analysis suggests an expansion or reconfiguration of the nature of writing instruction, that we introduce digital writing alongside more traditional forms of literacy that are normally institutionally sanctioned. Self-sponsored digital literacy not only speaks to the ongoing developments in our language and our modes of communication, it is also a deep resource for literacy instruction.

\section{The Bigger Picture}

Acknowledging the validity of digital literacy-and using it as a resource for increasing academic literacy-is useful on the practical level within the classroom, but it is important to note that pedagogical implications may also exist on an even larger scale. The analysis made earlier certainly stresses the broader idea that digital literacy does not negatively influence standard forms of literacy; in fact quite the opposite is true. Craig (2003) insists on this point, noting that text-speak does not have a negative impact on other forms of literacy for three distinct reasons. First, phonetic playing with language leads to improved literacy as a whole. Language play is a metalinguistic skill, one that depends upon students' knowledge of their language and cognitive awareness of how it functions. Secondly, literacies can and do develop independently of each other. And finally, languages evolve over time, and the proliferation of text-speak is just one example of this (Craig, 2003).

Viewing literacy on an even larger sociological scale, we have seen that literacies that are marked as good or high are practiced by those in economic and political power, namely the upper class. Literacies marked as bad or low are usually seen as practiced by those in the margins (Purcell-Gates, 2007). What if the propagation of a type of literacy that is prevalent among groups representing a spectrum of sociological markers, including across all class statuses, is able to play a role in disassembling this power structure? Surely, digital literacy is marked as a low literacy-there have been countless laments of text-speak creeping into 
academic writing-and academic literacy will undoubtedly continue to be positioned as a high and strongly valued literacy. But it seems from our analysis that digital literacy has been more ubiquitous in use among various social and class groups than previously researched forms of vernacular literacy (such as Black English). That is to say, it is not valued primarily by one class or differently by race or gender. To be sure, digital writing is not free from influence by such sociological markers; however, being literate in digital rhetoric is given strong value and social significance across all of these social markers. Such value making is an important consideration in terms of power and status maintenance.

Textual validation is also an important pedagogical tool. By validating literacies that are commonplace in a person's everyday home and community life, such as digital literacy, an instructor would in effect motivate students in the classroom through such acknowledgement (Purcell-Gates, 2007). Not only can selfsponsored literacies act as a bridge to academic literacy, it provides-through validating extra-institutional literacies-an opportunity for discourse that explores and critiques the dominant academic literacy.

The reason digital literacy is such a deep resource for pedagogical instruction, then, is because it validates self-sponsored vernacular literacies, and exposes students to their ability to code-switch and use language contextually. It follows that the answer to why it is important for educators to acknowledge and make use of digital literacy is extraordinarily manifold. It is vital because language is evolving, literacy is steeped in social status, and it is metalinguistic language play. It also gives power to students by acknowledging the communicative power and validity of their vernacular, and opens the possibility for a disassembling of the power structure that is set in place by dominant literacies. Most importantly, since it is an extremely accessible type of literacy across all sociological groups, it is a resource worth using in the classroom. Digital literacy is, without a doubt, less hierarchal and more accessible than standard academic literacy. It is possible to use its accessibility to play with and break open the power structure, and simultaneously to teach contextual literacy usages of appropriate (and the word 'appropriate' is key here, not 'right' or 'wrong') rhetoric for matching to specific contexts. And of course, in the spirit of our ever-evolving language, such contextual boundaries should be pushed.

\section{Limitations and Suggestions for Further Research}

This analysis employs a somewhat distant and broad scope in order to give a biggerpicture view of how one might combine multiliteracies and sociological considerations to investigate digital literacy. This application could certainly be narrowed in various ways-thinking about digital literacy from a sociological standpoint opens up tremendous opportunities for further analysis. For instance, one might look more closely at the different types or genres of digital literacies that are widely used, and query how status and value operate in each specific context. Do certain textual conventions appear in only some genres? Do others span platforms? 
Giving digital writing a close reading would also be a worthwhile endeavor, as there is surely much to uncover by examining sentence level structure, spelling conventions, and other characteristics unique to digital rhetoric. How are such conventions perceived by those who use them? By those who opt not to use them? One might also look more closely at how digital literacy conventions are shaped by formal constraints (the keyboard, Swype-style keypads, limited character space), and interrogate how such constraints influence textual choices. A close reading could also aim to uncover the cultural status attached to specific conventions by different producers of digital text, as well as explore the relationship between conventions and restrictions of form.

Lastly, though I have proposed that access is more open and thus beneficial, instead of restrictive, when it comes to digital literacy, important research is being done in the field of sociology on the digital divide's role as access increases. As noted previously, Hargittai and Hinnant (2008) have found that though the digital divide is shrinking in terms of access among classes, class status still strongly affects how computers are used. They find that higher classes tend to use Internet access for capital-building activities, to which access and knowledge about is still restricted in lower classes. It is worth investigating if and how this translates to digital literacy, or rather, if differences in usage among socioeconomic classes indicate differences in access to and usage of digital literacy.

\section{Conclusion}

This analysis has attempted to approach digital literacy from a sociological viewpoint. It was found that, in accordance with New Literacy Studies' conceptualization of literacy as pluralistic, digital literacy is but one of many literacies, and is equally legitimate as a form of writing. This paper also determined that because of the relationship between a literacy's perceived value and status in specific social contexts, digital literacy is employed by students, even in contexts deemed inappropriate, because their social and cultural group attach value and meaning to being digitally literate. Finally, this paper proposed that the digital divide has shrunk so considerably that access to digital literacy is incredibly widespread, and such accessibility makes it an exceptionally valuable resource in the classroom.

What, then, do we conclude from marrying these conclusions? We now see that digital literacy is a textually valid form of written communication, one that is steeped with user-beneficial social and cultural capital which leads to its use both in the appropriate context and out of context, and is a form of literacy that, due to its widespread use across various sociological vectors, is arguably more accessible to all socioeconomic levels than other types of literacy. These findings indicate that digital literacy is both worthy of sociological analysis, and a truly important pedagogical resource that it would be unwise to ignore. Introducing digital rhetoric into academic literacy instruction could prove to be beneficial on numerous levels. It acknowledges students' self-sponsored writing, empowers students by institutionally validating their socially prestigious literacy, and opens up the 
possibility for dissecting the power structure that reveres Standard English literacy. It enables students to recognize their highly useful ability to code-switch, and opens up dialogue about context and matching the appropriate literacy to its appropriate context. Lastly, there is the opportunity for skill transference between digital and academic literacies: by transferring specific skills from areas in which they are highly literate, students can strengthen other areas in which they are less literate.

It is undeniable that a vast majority of a high school or college students' writing now takes place in digital contexts. As we explored earlier, this is having an unmistakable influence on our language, and has introduced whole new types of communication that are rife with their own social codes, rules, and judgments of validity. While the point of literacy instruction is arguably to give students the tools necessary for expression, especially in academic Standard English contexts, we recognize that literacy is not an autonomous action that serves one purpose or takes one form. Just as Camitta deduced that students' handwritten notes passed between friends was useful for exploring literacy and an untapped resource for literacy instruction, I propose the same can be thought of digital writing. In fact, given that extra-institutional digital communication is socially legitimized and an extraordinarily accessible form of literacy, self-sponsored digital rhetoric is even more fruitful for both study on a sociological level and as a resource for instruction in academic literacy.

\section{References}

Barton, D. (2000). Researching literacy practices: Learning from activities with teachers and students. In D. Barton, M. Hamilton, \& R. Ivanič (Eds.), Situated literacies: Reading and writing in context (pp. 167-179). New York, NY: Routledge.

Bourdieu, P. (2008). The forms of capital. In N. Woolsey Biggart (Ed.), Readings in economic sociology (pp. 280-291). Hoboken, NJ: Wiley-Blackwell.

Camitta, M. (1993). Vernacular writing: Varieties of literacy among Philadelphia high school students. In B. Street (Ed.), Cross-cultural approaches to literacy (pp. 228-246). Cambridge, UK: Cambridge University Press.

Cazden, C., Cope, B., Fairclough, N., Gee, J., Kalantzis, M., Kress, G., ... Nakata, M. (1996). A pedagogy of multiliteracies: Designing social futures. Harvard Educational Review, 66(1), 60-92.

Cook-Gumperz, J. (2006). Literacy and schooling: An unchanging equation? In J. Cook-Gumperz (Ed.), The social construction of literacy (2nd ed., pp. 19-49). Cambridge, UK: Cambridge University Press.

Craig, D. (2003). Instant messaging: The language of youth literacy. Retrieved from http://bootheprize.stanford.edu/0203/PWR-Boothe-Craig.pdf

Frow, J. (2010). On midlevel concepts. New Literary History, 41(2), 237-252. 
Hargittai, E., \& Hinnant, A. (2008). Digital inequality differences in young adults' use of the Internet. Communication Research, 35(5), 602-621.

Jansen, J. (2010). Use of the Internet in higher-income households. Retrieved from Pew Research Center, Pew Internet \& American Life Project site: http://pewinternet.org/Reports/2010/Better-offhouseholds/Overview.aspx

Lareau, A. (2011). Unequal childhoods: Class, race, and family life (2nd ed.). Berkeley, CA: University of California Press.

Lenhart, A., Ling, R., Campbell, S., \& Purcell, K. (2010). Teens and mobile phones. Retrieved from Pew Research Center, Pew Internet \& American Life Project site: $\quad$ http://www.pewinternet.org/Reports/2010/Teens-and-MobilePhones/Summary-of-findings.aspx

Lenhart, A., Purcell, K., Smith, A., \& Zickuhr, K. (2010). Social media \& mobile Internet use among teens and young adults. Retrieved from Pew Research Center, Pew Internet \& American Life Project: http://www.pewinternet.org/Reports/2010/Social-Media-and-YoungAdults/Summary-of-Findings.aspx

Liu, A. (2010). From reading to social computing. Retrieved from Literary Studies in the Digital Age: http://dlsanthology.commons.mla.org/from-reading-tosocial-computing/

Madden, M., Lenhart, A., Duggan, M., Cortesi, S., \& Gasser, U. (2013). Teens and technology 2013. Retrieved from Pew Research Center, Pew Internet \& American Life Project: http://pewinternet.org/Reports/2013/Teens-andTech/Summary-of-Findings.aspx

Moretti, F. (2000). Conjectures on world literature. New Left Review, 1, 54-68.

Purcell-Gates, V. (2007). Complicating the complex. In V. Purcell-Gates (Ed.), Cultural practices of literacy: Case studies of language, literacy, social practice and power (pp. 1-23). Mahwah, NJ: Lawrence Erlbaum.

Reardon, S. F., Valentino, R. A., \& Shores, K. A. (2012). Patterns of literacy among US students. The Future of Children, 22(2), 17-37.

Smith, A. (2010). Mobile Access 2010. Retrieved from Pew Research Center, Pew Internet \& American Life Project: http://www.pewinternet.org/Reports/2010/Mobile-Access2010/Summary-of-Findings.aspx

Street, B. (1984). Literacy in theory and practice (Vol. 9). Cambridge, UK: Cambridge University Press.

Turner, K. H. (2009). Flipping the switch: Code-switching from text-speak to standard English. English Journal, 98(5), 60-65. 
Warschauer, M. (2008). Whither the digital divide? In D. L. Kleinman, K. A. Cloud Hansen, C. Matta, \& J. Handesman (Eds.), Controversies in science \& technology: From climate to chromosomes. New Rochelle, NY: Liebert.

Zickuhr, K. (2010). Generations 2010. Retrieved from Pew Research Center, Pew Internet \& American Life Project: http://pewinternet.org/Reports/2010/Generations-2010/Overview.aspx

Zickuhr, K. (2011). Generations and their gadgets. Retrieved from Pew Research Center, Pew Internet \& American Life Project: http://www.pewinternet.org/Reports/2011/Generations-andgadgets/Overview.aspx 